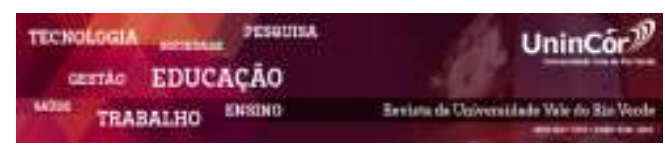

Revista da Universidade Vale do Rio Verde ISSN: 1517-0276 / EISSN: 2236-5362 Vol. $16 \mid$ n. 1 | Ano 2018

Letícia Rodrigues da Fonseca Universidade Vale do Rio Verde (UninCor) leticia.rodrigues.vga@gmail.com

Sergio Ricardo Magalhães Universidade Vale do Rio Verde (UninCor) sergio.magalhaes@unincor.edu.br

Júnia Rafael Mendonça Figueiredo Universidade Vale do Rio Verde (UninCor) junia_rmfigueiredo@hotmail.com

Glei dos Anjos de Carvalho Castro Universidade Vale do Rio Verde (UninCor) gleicarv@yahoo.com.br

Leopoldo Uberto Ribeiro Júnior Centro Universitário de Itajubá (FEPI) leopoldojunior@yahoo.com.br

Guilherme Marques Pereira Universidade Vale do Sapucaí (UNIVAS) guilherme.marques@bol.com.br

\section{ANÁLISE DOS TRAÇOS CULTURAIS BRASILEIROS: Um estudo em uma organização nacional do ramo de confecção e vestuário}

\section{RESUMO}

O presente estudo analisou as manifestação dos traços culturais "Jeitinho" e "Sociedade Relacional" em uma organização do ramo de confecção e vestuário localizada no estado de Minas Gerais. Para isso foi realizado um estudo exploratório-descritivo, de abordagem quantitativa, que utilizou o instrumento desenvolvido e validado por Fernandes (2006), cuja elaboração baseou-se nos ensaios teóricos de Freyre (2004), Holanda (1995), Ribeiro (2006) e Da Mata $(1978 ; 1984)$. Foi utilizada uma amostra nãoprobabilística de 127 questionários coletados no período de 26 a 30/10/2016. Os resultados demonstraram que ambos os traços se manifestam da mesma maneira para homens e mulheres, para funcionários de diferentes faixas de idade, para funcionários de diferentes níveis de escolaridade, para funcionários cuja função envolve ou não coordenação de pessoas, e para aquelas que possuem maior ou menor tempo de empresa, o que evidencia a penetração dos referidos traços em vários segmentos da sociedade, classificando-os, portanto, como traços culturais da cultura brasileira.

Palavras-chave: Cultura Brasileira; Cultura Organizacional; Traço Cultural.

\section{ANALYSIS OF BRAZILIAN CULTURAL TRACES: A study in a national organization of the clothing and apparel sector}

\begin{abstract}
The present study analyzed the manifestations of the cultural traits "Jeitinho" and "Sociedade Relacional" in an organization of the garment and clothing branch located in the state of Minas Gerais. For this, an exploratory-descriptive study was carried out, using a quantitative approach, using the instrument developed and validated by Fernandes (2006), whose elaboration was based on the theoretical essays of Freyre (2004), Holanda (1995), Ribeiro (2006) and Da Mata $(1978,1984)$. A non-probabilistic sample of 127 questionnaires collected in the period from October 26 to October 30, 1616 was used. The results showed that both traits manifest themselves in the same way for men and women, for employees of different age groups, for employees of different levels of education, for employees whose function involves or not coordination of people, and for those who have higher or shorter company time, which shows the penetration of these traits in various segments of society, thus classifying them as cultural traits of Brazilian culture.
\end{abstract}

Keywords: Brazilian culture; Organizational culture; Cultural Trait. 


\section{INTRODUÇÃO}

O Brasil, devido a influência de diferentes grupos imigrantes, desde o seu período de colonização, desenvolveu uma cultura própria e diferenciada. Segundo Pinto (2005), a colonização foi realizada oficialmente por portugueses, mas houve forte influência dos índios que já viviam no país no momento de seu descobrimento, como de negros e de outros povos, que ao longo da história, vieram para o país, como japoneses, italianos, árabes, franceses, alemães, holandeses entre outros.

Ainda, de acordo com Barros (2005), a cultura brasileira com suas características e especificidades, como outras culturas, impacta o modelo de gestão das empresas. Segundo a autora, as soluções gerenciais não são universais, já que nos países onde não se compartilham as crenças quanto a estes métodos, torna-se difícil o seu entendimento e aplicação, e quando isso ocorre, a solução não é aceita facilmente.

Aspectos importantes sobre a cultura organizacional podem ser identificados a partir de traços culturais. Em um levantamento sobre os estudos da Cultura Brasileira escrito por Alcadipani e Crubelatte (2003), os autores identificaram que muitas pesquisas confirmavam a presença de traços culturais nítidos e decifráveis que afetavam as organizações, formando uma cultura organizacional brasileira.

Diante deste cenário e inspirando-se na pesquisa de Fernandes (2006), que visou analisar traços culturais brasileiros em uma organização nacional com o intuito de oferecer subsídios a gestão organizacional, o presente artigo possui o intuito de responder o seguinte questionamento: os traços culturais "sociedade relacional" e "jeitinho", presentes em uma organização nacional do ramo de confecção e vestuário, se manifestam de maneira diferente, conforme o perfil do colaborador?

Pretende-se ainda neste estudo, identificar quais destes traços estão presentes com maior ênfase, bem como verificar possíveis relações entre estes traços e as variáveis demográficas utilizadas.

\section{REFERENCIAL TEÓRICO}

\subsection{Cultura Nacional, Cultura Brasileira e Cultura Organizacional}

De acordo com Barros (2005), a cultura nacional refere-se aos valores, crenças e costumes aprendidos desde a infância que diferenciam um grupo de pessoas de um país ou região. Durante toda a nossa vida seremos moldados conforme o meio ambiente em que estamos inseridos.

Em seu estudo sobre as diferenças culturais entre países, Hofstede (1999), identificou que a cultura nacional influenciava nas relações mantidas por indivíduos de países distintos com o trabalho. Portanto, devido a essa cultura peculiar brasileira, acredita-se ser de suma importância compreender um pouco mais sobre a forma de pensar e agir do brasileiro, visando oferecer subsídios para a gestão organizacional.

Segundo Silva e Luna (2004), o Brasil é visto pela maioria de seus analistas como um país 
de grande diversidade cultural, desde a sua formação, pela mistura de raças, até a sua extensão que levou a construção de grandes diferenças regionais e à proliferação de costumes bastante distintos, apesar do compartilhamento da nacionalidade e, na maioria dos casos, do idioma.

Para Hanashiro e Godoy (2004), as empresas brasileiras vêm passando por intensos processos de fusões e aquisições de novos negócios, visando ampliar a sua competitividade. Nestes processos, os empregados passam a conviver com estilos de gestão, sistemas, normas e padrões de comportamento diferentes. A globalização econômica e de mercados ampliou as possibilidades de se trabalhar com equipes mais heterogêneas, quanto à nacionalidade, raça, hábitos e valores diferentes. Os avanços tecnológicos permitiram interações entre pessoas de diversas regiões distintas em termos culturais. Soma-se a isso o fato de, hoje, as pessoas estarem mais conscientes de suas diferenças e desejarem vê-las respeitadas e valorizadas. Ainda, de acordo com as autoras, a presença de diversidade nas organizações afetará seus resultados individuais e organizacionais. O "clima da diversidade" é o eixo que determinará se esse resultado será positivo ou negativo.

O termo cultura organizacional não é algo recente. Segundo Pépin (1998), o primeiro pesquisador a utilizar o termo cultura para descrever uma organização foi Elliot Jaques em seus estudos, na Inglaterra, em 1951. Após ter desaparecido quase que por completo das pesquisas organizacionais, o termo cultura corporativa voltou a ser discutido nos trabalhos de Pettigrew em 1979.

Para Schein (1992), um dos autores mais citados nos estudos sobre cultura organizacional, cultura seria um modelo de pressupostos básicos que um dado grupo inventou, descobriu ou desenvolveu aprendendo a lidar com problemas de adaptação externa e integração interna que, suficientemente bem trabalhado para ser considerado válido, pode, em seguida, ser apresentado para os novos membros como o modo correto de perceber, pensar e sentir em relação a esses problemas.

O autor afirmar que se quisermos tornar uma organização eficaz, deveremos entender o papel da cultura na vida organizacional. A cultura organizacional é importante para a gestão das empresas, pois tanto a estratégia e os objetivos, quanto o modo de operação da empresa e o comportamento das pessoas, são influenciados pelos elementos culturais.

\subsection{Traços Culturais Brasileiros}

Traços culturais brasileiros são como "pressupostos básicos que cada indivíduo usa para enxergar a si mesmo como brasileiro" (FREITAS, 1997, p.39).

No levantamento sobre os estudos da Cultura Brasileira realizado por Alcadipani e Crubelatte (2003), os autores identificaram pesquisas que confirmavam a presença de traços culturais que afetavam as organizações, formando uma cultura brasileira. Ainda, quanto a estes estudos, os autores observaram que a maioria eram ensaios teóricos que procuravam as raízes dos traços nacionais desde os primórdios do Brasil até a atualidade, fundamentando-se nas obras dos autores Gilberto Freyre, Sérgio Buarque de Holanda, Caio Prado Junior, Raymundo Faoro, Darcy Ribeiro e Roberto Da Matta. 
Igualmente, Fernandes (2006) em sua pesquisa identificou cinco traços culturais brasileiros denominados hierarquia, ambiguidade, sociedade relacional, jeitinho e malandragem, baseados nas obras de Freyre (2004), Holanda (1995), Ribeiro (2006) e DaMata (1978;1984).

Gilberto Freire, um dos principais estudiosos da identidade do Brasil e do brasileiro, escreveu importantes obras de interpretação da cultura brasileira. A obra eleita por Fernandes (2006), para análise foi a sua primeira e uma das mais famosas "Casa Grande \& Senzala", escrita em 1933.

De acordo com Freire (2004), os termos "casa-grande" e "senzala" foram utilizados como uma metáfora do Brasil colonial, a atividade econômica exercida era a monocultura açucareira que contribuiu para o surgimento de uma sociedade patriarcal, agrária, escravista e mestiça. A colonização realizada pelas famílias portuguesas visava apenas retorno financeiro e não o inicio de uma civilização. Ao se assentarem, conquistando o seu espaço, estas famílias obtinham título de nobreza, o Estado não possuía nenhuma influência neste processo de colonização. A sociedade brasileira se iniciou a partir das relações entre as raças branca, indígena e negra. Os índios foram influenciados pelos colonizadores europeus através do ensino religioso, realizado pela "Companhia de Jesus" e tiveram que se adaptar ao trabalho nas lavouras, as missões jesuítas, as relações sexuais ou ao enclausuramento nas matas.

Igualmente, segundo o autor, os negros mantinham relações de trabalho e sexuais com os portugueses. Os portugueses misturavam-se facilmente com as outras raças, não demonstrando "superioridade racial", devido a sua atividade comercial com diferentes povos. O catolicismo atuava como uma liga da sociedade colonizadora. Todos eram aceitos, desde que fossem católicos. As famílias colonizadoras mais expressivas situavam-se nas regiões de Pernambuco e Bahia e eram retratadas como aristocratas agrários, preocupadas em manter o status de nobreza como senhores de engenho. A relação entre os senhores rurais e os que estavam a sua volta, expressava a cobrança de obediência e lealdade em troca de proteção. Freire (2004), apresenta a sociedade patriarcal e escravocrata como açucarada, no entanto, não nega a violência que existia nas relações entre os senhores de engenho e seus escravos. O negro africano também é apresentado como colonizador, mas dentro da lógica da escravidão. Sua colonização deu-se através do sexo forçado pelo senhor da casa grande, onde surgia um filho mulato. Devido ao trabalho doméstico, os negros mantinham uma relação íntima com a casa grande, estes tinham que se sujeitar a todas as ordens impostas pelos senhores para garantir a sua sobrevivência. Desta relação mantida entre negros e brancos, envolvendo relações de poder e sobrevivência, surgia uma cultura peculiar brasileira, devido à fusão de seus idiomas, práticas, crenças e das representações de poder.

Com o mesmo intuito, Sérgio Buarque de Holanda, três anos após o lançamento de "Casa Grande \& Senzala", publicou o livro "Raízes do Brasil", obra que pretendia traçar o perfil da sociedade brasileira.

Para Holanda (1995), a influência de Portugal na formação da cultura brasileira é maior em relação ao que foi exposto por Freire (2004). No entanto, as características referentes a cultura portuguesa relatadas por ambos são semelhantes. 
Em sua obra "Raízes do Brasil” Holanda (1995), afirma que o português é aventureiro, e o seu perfil de colonizador é devido a este espírito de aventura. Valoriza mais as suas conquistas do que os frutos que suas colônias podem oferecer. Não se adaptava ao trabalho agrícola, portanto, a mãode-obra escrava era fundamental. Provavelmente, devido a essa personalidade aventureira é que o português se adaptou facilmente aos trópicos em relação ao holandês. Por ser um povo miscigenado, não sentiam orgulho de sua raça. Como os portugueses não se preocupavam em cuidar do solo, este se deteriorou, o que ocasionou a adoção de muitas técnicas indígenas de produção agrícola. Ao se aproximar dos índios, estes obterão certa proteção distanciando-se um pouco do regime de escravidão. O único trabalho conhecido no Brasil era o escravo, o trabalho mecânico era desprezado. Os brasileiros não eram solitários.. Os colonos holandeses possuíam um caráter urbano que não se adequava ao Brasil e não colocavam em prática esforços para se fixar no país. A igreja católica contribuiu consideravelmente com a colonização por manter relações mais harmoniosas em relação às igrejas protestantes. Outro fator importante foi a língua portuguesa que era mais fácil de ser aprendida por índios e negros.

Segundo Holanda (1995) entre 1851 e 1855, houve um considerável desenvolvimento urbano devido a construção das estradas de ferro. Este desenvolvimento esteve muito relacionado com a eliminação do tráfego negreiro. Visões do mundo tradicional e moderno geraram conflito, o país não possuía estrutura econômica, política e social para desenvolver a indústria e comércio. $\mathrm{O}$ engenho era visto como uma micro-sociedade, as leis externas não eram aplicadas, o poder era restrito aos senhores rurais. $O$ restante da sociedade era dominado pelo patriarca. Em um determinado momento os homens que vinham para a cidade eram aqueles que possuíam status e importância no campo. O sentimento de nobreza e aversão ao trabalho oriundos da Casa Grade invadiram as cidades, o que retrata a dificuldade no período da independência de ultrapassar os limites políticos gerados pela colonização portuguesa. Os portugueses eram mais liberais que os espanhóis, no entanto, mantiveram firme o pacto que proibia a produção de muitas manufaturas em suas colônias. Os portugueses possuíam maior flexibilidade social, não possuíam tradição ou orgulho da classe, portanto, desejam fazer parte da nobreza. Homens que possuíam posições públicas tinham dificuldades em diferenciar o público e o privado. O brasileiro mostra-se ser cordial, de bom trato, no entanto, para que alguém seja digno de confiança, é necessário conhecê-lo primeiro.

Dentre os autores selecionados neste estudo, Darcy Ribeiro foi aquele que analisou as diferenças socioculturais em diversas regiões brasileiras com maior riqueza de detalhes em sua obra intitulada "Povo Brasileiro", publicada em 1995.

Em sua obra Ribeiro (2006) apud Fernandes (2006), relata que o Brasil seria formado por um povo novo que surgiu a partir de uma etnia nacional com cultura diferente de suas matrizes formadoras, fortemente mestiçada. Segundo o autor a "gestação do Brasil" e a dos brasileiros ocorreu por meio da união entre portugueses, índios e negros, matrizes étnicas do brasileiro. Essa mestiçagem fez nascer um novo gênero humano. A história brasileira divide-se em cinco formadores regionais: crioula, cabocla, 
gaúcha, caipira e sertaneja. Para Ribeiro, formamos uma "Nova Roma", a maior presença neolatina no mundo. O núcleo crioulo surgiu no litoral nordestino por meio da fusão de brancos, negros e índios em torno dos engenhos açucareiros. Nesta sociedade existia a figura dos senhores de engenhos e dos escravos fundidos. O senhor de engenho era um empresário nativo, o escravo negro ou índio mesmo de uma raça diferente, tinha mais em comum com esse senhor do que com seus ancestrais, pois compartilhavam a mesma língua e visão de mundo. A família patriarcal não possibilitava formas dignas de acasalamento para negros e mestiços. Os senhores de engenho e seus filhos eram livres para manterem relações sexuais com estes indivíduos. Todos eram subordinados ao senhor de engenho, mesmo o clero ou a administração do reino não exerciam influência. As leis e as normas vigentes representavam o formalismo, no entanto, este deu origem ao Jeitinho na época da invasão Holandesa no Nordeste. Os senhores de engenho não apresentaram resistência à invasão visto que os Holandeses ofereceram financiamentos para a melhoria dos negócios que permitiu a renovação das instalações e da escravaria.

O núcleo caboclo, conforme Ribeiro (2006), refere-se à população amazônica que vivia do extrativismo vegetal e mineral. A empresa extrativista vegetal exercia o mesmo poder que um senhor de engenho. O papel dos índios nesta sociedade era ensinar os meios de sobrevivência na mata. A mestiçagem de brancos com índias foi incentivada pela coroa, já que as mulheres portuguesas estavam incapacitadas de atender os apelos. A mão-de-obra era recrutada e mantida por meio de um sistema de endividamento. O núcleo sertanejo localizava-se no Nordeste até os cerrados do Centro-Oeste e era formado por uma população de pastores que eram responsáveis pelas criações de gado dos senhores de engenho da costa. O regime de trabalho se baseava no pagamento por meio de gêneros de manutenção ou crias do rebanho. As famílias dos vaqueiros e seus ajudantes moravam nos currais. Nas relações mantidas com os donos da terra prevalecia a hierarquia, mas não com tanta ênfase como nas relações com o senhor de engenho. Existia convívio intenso entre o senhor e seus serviçais, no entanto, as classes não se aproximavam socialmente, mesmo relações de compadrio e apadrinhamento. $\mathrm{O}$ vaqueiro mantinha uma relação de respeito, obediência e lealdade para com o seu senhor, seu maior medo era se ver desgarrado, sem o patrão que o protegeria da polícia, juiz ou cobrador de impostos. Como ficavam ilhados no latifúndio pastoril não queriam ser excluídos de seu grupo. No sistema colonial do latifúndio pastoril, o cangaceiro era o sertanejo que atuava como jagunço e vingador do coronel. Outra característica do sertanejo era o seu fanatismo religioso nas crenças messiânicas.

Ainda, segundo o autor, o núcleo caipira ocupava toda a área florestal do centro sul do país, desde São Paulo, Espírito Santo, Rio Janeiro, Minas Gerais e Mato Grosso. Era nesta área antiga em que paulistas buscavam ouro, com o término da mineração surgiu uma população dispersa e desarticulada. A população caipira mantinha sua sobrevivência através da colaboração e mutirões. Aqueles que fugiam deste convívio, penetrando sós no sertão, eram vistos como gente suspeita. Após o período de 1970 a 1840 surgiram novas formas de produção agroexportadora e com elas a instalação de um poder estatal mais efetivo. Este estado 
representava a camada proprietária e o obrigava a uma sujeição. O amparo de um senhorio, seu "cumpadre", que oferecia proteção era essencial. O seu maior medo era se ver sozinho frente a essa ordem social que se alastrava pelo mundo. Com o crescimento do café e com o caipira resistindo ao regime de fazenda semelhante ao trabalho escravo, e com a existência de milhões de caipiras subocupados, o sistema de fazendas apelou para a imigração européia maciça. A formação do Brasil Sulino também foi resultado da ocupação paulista na antiga região de prévia dominação espanhola. Sua formação é proveniente de três matrizes, os lavradores matutos de origem açoriana que ocupavam a faixa litoral do Paraná para o sul, os gaúchos da zona de campos da fronteira rioplatense e bolsões pastoris Catarinenses, e os gringos brasileiros, descendentes de europeus, ilhados na zona central e avançando sobre as duas outras áreas. A coexistência destes três complexos os torna homogêneo com a difusão de traços e costumes de um ao outro. Quanto ao estanceiro e o gaúcho, a união entre patrão e empregado ocorria nas cavalgadas e nas provas de maestria como boleadores e laçadores de reses bravias. O patrão vivia cercado pelos seus peões que lhe preparavam erva, assavam churrasco e combinavam encontros com as chivas vizinhas. Havia uma forte parceria entre os gaúchos lavradores de terras alheias e os donos das referidas. Como os lavradores eram dependentes dos proprietário, aceitam pagar a metade ou a terça parte da colheita, além de lhe dedicar lealdade pessoal e política.

Neste estudo serão analisadas ainda as obras de Roberto DaMatta, "Carnavais, Malandros e Heróis" publicada em 1978 e "O que faz o brasil, Brasil", publicada em 1984. Ao contrario dos outros autores DaMatta não focalizou o estudo das raças, mas os rituais e personagens. Suas obras foram publicadas em um contexto bem diferente da década de 30, época em que as obras dos demais autores citados neste estudo foram publicadas. Sua análise focaliza um Brasil mais urbano, onde a sociedade carioca tem grande influência.

DaMatta $(1978 ; 1984)$, visa em sua obra “ Carnavais, Malandros e Heróis", compreender não o que possuímos de histórico e datado mas aquilo que se mostra permanente e duradouro, Para o autor, os valores, as relações, os grupos sociais e ideologias que pretendem estar ao lado e acima do tempo, é que definem, o caráter ou a cultura de uma sociedade. O lado autoritário e hierarquizado da sociedade brasileira possui três dimensões: existência de uma ordem formal, baseada em posições de status e prestígio social, onde não existem conflitos e onde "cada um sabe o seu lugar"; a existência de uma oposição entre o mundo das "pessoas", socialmente reconhecidas em seus direitos e privilégios, e um universo igualitário dos indivíduos, onde as leis impessoais funcionam como instrumentos de opressão e de controle ("para os amigos, tudo; para os inimigos, a lei"); e o mundo do sagrado, onde existiria uma suposta equalização da sociedade, já que todos são filhos de Deus, mas ao mesmo tempo são mantidas estruturas claramente hierárquicas de santidade.

Segundo o autor, estes sistemas hierarquizados promovem uma dissociação entre dois mundos ideais na cultura brasileira: o mundo da casa, onde as pessoas valem pelo que são, onde perpetua a harmonia, e o mundo da rua, onde os indivíduos "lutam pela vida". As principais armas utilizadas de maneira alternada nesta batalha são a 
afirmação dos privilégios de status das pessoas das classes dominantes ("você sabe com quem está falando?") e a redução dos indivíduos às leis impiedosas do mercado e da burocracia. As paradas, as procissões e o "você sabe com quem está falando?" ritualizam e explicitam os aspectos hierárquicos e autoritários da sociedade brasileira. Já, o carnaval é igualitário, nos seus três dias expõem ideais das relações espontâneas e afetivas para o mundo da "rua". A negação que o carnaval parte das estruturas de poder e autoridade é representada pela figura do malandro. O malandro, em oposto ao herói, não busca dominar a estrutura do poder e a ela se sobrepor sendo reabsorvido por ela. Ele vive nas brechas do sistema, de seus absurdos e de suas contradições. Nos rituais, especialmente nos coletivos, as pessoas tem uma visão alternativa de si mesmos. Por exemplo, no Brasil durante o carnaval os pobres viram ricos, não há influencia do viés hierárquico/repressivo da sociedade. Para DaMatta, o carnaval, as paradas militares, as procissões (rituais brasileiros), são vistos como dramatização dos valores, ideologia e relações da sociedade. DaMatta, analisa a diferenciação entre as pessoas por meio do conceito de individuo e pessoa. Indivíduo e a entidade social pertencente a massa, sujeito as leis impessoais que governam aqueles que não tem boas relações. A pessoa estaria sujeita a relações cordiais, provenientes do coração, do intimo, familiar e privado. Algumas expressões como "dia-a-dia"e "dura realidade da vida" retratam a hierarquia do poder ilustrada pelo "sabe com quem está falando?". A aversão as regras é retratada pelo "Caxias" (pessoa preocupada em seguir as normas), uma alusão ao patrono do exército nacional

Os traços que serão abordados neste estudo serão "Sociedade Relacional"e "Jeitinho".
De acordo com Fernandes (2006), o "Jeitinho", muitas vezes chamado de "Jeitinho Brasileiro", o tom emotivo e o desejo de intimidade, adotados frequentemente nas relações pessoais, são vistos como traços marcantes por estrangeiros que visitam o Brasil.O autor analisou este traço conforme os sub-traços "Formalismo" e "Flexibilidade". Espera-se que alguém que seja adepto do "Jeitinho" perceba: a existência de regras inadequadas à prática social; a necessidade de flexibilização na aplicação de regras; a necessidade de contornar regras visando resolver problemas ou situações especiais; a necessidade de ajudar alguém ou dar andamento ao trabalho como prioridade, mesmo que regras tenham de ser contornadas.

Já o traço "Sociedade Relacional", foi analisado de acordo com o sub-traço "Lealdade às Pessoas". Espera-se que alguém que apresente este traço perceba que: as pessoas procuram estabelecer relacionamentos pessoais no trabalho; as pessoas procuram estabelecer relações pessoais com seu chefe; o ambiente de trabalho é uma extensão do ambiente familiar; as relações impessoais tendem a dar lugar às relações de confiança (pessoais); o trabalho é mais produtivo quando realizado com as pessoas com as quais há um relacionamento pessoal.

\section{METODOLOGIA}

Com o objetivo de identificar se os traços culturais "sociedade relacional" e "jeitinho", presentes em uma organização nacional do ramo de confecção e vestuário, se manifestam de maneira diferente conforme o perfil do colaborador, foi realizado um estudo exploratório 
descritivo, com abordagem quantitativa. Para Gil (1999), as pesquisas exploratórias têm como principal finalidade desenvolver, esclarecer e modificar conceitos e idéias, tendo em vista, a formulação de problemas mais precisos ou hipóteses pesquisáveis para estudos posteriores. Já, as pesquisas descritivas, visam descrever as características de uma determinada população ou o estabelecimento de relações entre variáveis. Uma de suas características mais significativas está na utilização de procedimentos padronizados de coleta de dados.

A presença dos traços foi mensurada por meio de um instrumento construído e validado por Fernandes (2006). Em seu trabalho, o autor identificou cinco traços culturais brasileiros: hierarquia, ambiguidade, sociedade relacional, jeitinho e malandragem. As definições dos referidos traços foram baseadas nos ensaios teóricos de Freyre (2004), Holanda (1995), Ribeiro (2006) e DaMata (1978;1984). Devido a limitação do escopo de seu trabalho Fernandes (2006) abordou apenas dois dentre os cinco traços culturais: sociedade relacional e jeitinho. $\mathrm{O}$ instrumento é composto por 21 questões, sendo 9 relacionadas ao traço "jeitinho" e 12 relacionadas ao traço "sociedade relacional", e possui uma escala de 1 a 6 , sendo 1 discordo totalmente e 6 concordo totalmente.

\subsection{A Empresa Pesquisada e a Coleta de Dados}

O questionário foi respondido por funcionários de uma empresa do ramo de confecção e vestuário localizada no estado de Minas Gerais. Esta organização presente no país há quase 10 anos possui 454 funcionários. Foram distribuídos 200 questionários no período de 26 a 30/10/2016, sendo obtido ao final um total de 127 questionários com respostas válidas.

\subsection{Técnicas de Análise}

Utilizou-se o software de análises estatísticas SPSS (PASW Statistics) versão 15, para se obter uma análise descritiva das variáveis demográficas e das variáveis relacionadas aos traços culturais de uma amostra não-probabilística de 127 respondentes.

Para verificar se os traços culturais se manifestariam da mesma maneira para as variáveis demográficas, foi realizado o teste não paramétrico Kruskal-Wallis. De acordo com Pereira (2006), as técnicas de estatística não paramétrica são particularmente adaptáveis aos dados das ciências do comportamento. A aplicação dessas técnicas não exige suposições quanto à distribuição da população da qual se tenha retirado amostras para análises. Podem ser aplicadas a dados que se disponham simplesmente em ordem, ou mesmo para estudo de variáveis nominais, contrariamente à estatística paramétrica, onde as variáveis são, na maioria das vezes, intervalares. Exigem poucos cálculos e são aplicáveis para análise de pequenas amostras.

Ainda, segundo Pereira (2006), o Kruskal-Wallis, trata-se de um teste para decidir se $\mathrm{K}$ amostras $(K>2)$ independentes provêm de populações com médias iguais. Pode-se utilizar este teste para aceitar a hipótese nula que afirma que as médias da população são as mesmas para os dois grupos. 


\section{APRESENTAÇÃO E DISCUSSÃO DOS RESULTADOS}

\subsection{Dados Demográficos}

Os dados de caracterização dos entrevistados demonstraram que 69,8\% dos pesquisados são do sexo masculino e $30,2 \%$ do sexo feminino. A maioria possui segundo grau completo $(47,2 \%)$, exerce função que envolve a coordenação de pessoas $(77 \%)$, possui até 3 anos de empresa $(56,1 \%)$, nasceu no estado de Minas Gerais (92,9\%), com idade de 29 anos ou acima (27\%).

\subsection{Resultado do Teste Não-Paramétrico Krus- kal-Wallis}

De acordo com os resultados obtidos por meio do teste não paramétrico Kruskal-Wallis, aceitou-se a hipótese de que os traços Jeitinho e Sociedade Relacional se manifestam da mesma maneira para homens e mulheres, para funcionários de diferentes faixas de idade, para funcionários de diferentes níveis de escolaridade, para funcionários cuja função envolve ou não coordenação de pessoas, e para aquelas que possuem maior ou menor tempo de empresa, visto que o nível de significância foi superior a 0,05 para todas as variáveis demográficas. Utilizou-se as mesmas variáveis criadas para a obtenção da média dos dois traços. É importante ressaltar que o mesmo resultado foi obtido no estudo de Fernandes (2006), ao se utilizar o teste paramétrico ANOVA.

Tabela 1 - Resultado do Teste Não-Paramétrico Kruskal-Wallis

\begin{tabular}{l|l|l|l|l|l} 
& Sexo & Idade & Escolaridade & Função & $\begin{array}{l}\text { Tempo } \\
\text { Empresa }\end{array}$ \\
\hline Jeitinho & 0,887 & 0,808 & 0,142 & 0,722 & 0,267 \\
\hline $\begin{array}{l}\text { Sociedade Rea- } \\
\text { cional }\end{array}$ & 0,767 & 0,190 & 0,195 & 0,117 & 0,210
\end{tabular}

Fonte: Elaborada pelos autores

\section{CONSIDERAÇÕES FINAIS}

O presente estudo visou identificar se os traços culturais "Sociedade Relacional" e "Jeitinho", presentes em uma organização nacional do ramo de confecção e vestuário, se difeririam conforme o perfil do colaborador de uma empresa nacional do ramo de confecção e vestuário localizada em Minas Gerais.
De acordo com os resultados obtidos por meio do teste não-paramétrico Kruskal-Wallis identificou-se que, quanto a manifestação deste dois traços, não há diferenças entre homens e mulheres, gestores e não gestores, diferentes faixas etárias, diferentes graus de escolaridade ou entre funcionários com maior ou menor tempo de empresa. 
A não identificação de diferenças quanto às manifestações destes traços, evidencia a penetração dos referidos em vários segmentos da sociedade, classificando-os, portanto, como traços culturais da cultura brasileira. Ë importante salientar que um resultado semelhante foi obtido pela pesquisa de Fernandes (2006).

Igualmente como Fernandes (2006), destaca-se como limitação deste estudo, a amostra não-probabilística utilizada de apenas uma organização localizada em um estado específico. Outro aspecto limitador foi o fato de que a maioria dos funcionários entrevistados eram nascido no estado onde se localiza esta empresa.

Como pesquisas futuras, sugere-se que a mesma pesquisa seja realizada em empresas do mesmo segmento presentes em diferentes estados.

\section{REFERÊNCIAS}

ALVESSON, Mats. Understanding organizational culture. London: SAGE Publications, 2002.

ALCADIPANI, Rafael; CRUBELATTE, João Marcelo. Cultura Organizacional: generalizações improváveis e conceituações imprecisas. Revista de Administração de Empresas - RAE, São Paulo, v.43, n.2, p.64-76, Abril/Maio/Junho, 2003.

BARROS, Betania Tanure de. Gestão à brasileira: somos ou não diferentes? : uma comparação entre América Latina, Estados Unidos, Europa e Ásia. 2. ed. São Paulo: Atlas, 2005.

CAMERON, Kim S.; QUINN, Robert E. Diagnosing and changing organizational culture.

Massachusetts: Addison-Wesley, 1999.

CZARNIAWSKA-JOERHES B. Culture is the medium of life. IN: FROST et al. Reframing organizational culture. Newbury Park, CA: Sage Publications, 1991.

DAMATTA, Roberto. Carnavais, Malandros e Heróis, para uma sociologia do dilema brasileiro. Rio de Janeiro: Rocco, 1978
DAMATTA, Roberto. O que faz o Brasil, Brasil? : Rocco, 1984.

DENISON, Daniel; MISHRA, Aneil. K. Toward theory of organizational culture and effectiveness. Organization Science. v.6, n.2, p. 204-223. MarchApril, 1995.

FERNANDES, Ricardo Antonio. Uma análise dos traços culturais brasileiros em uma organização nacional. 2006. Dissertação (Mestrado em Administração) - Programa de Pós-Graduação em Administração - Mestrado - Universidade Presbiteriana Mackenzie, São Paulo, 2006.

FREITAS, Alexandre Borges de. Traços brasileiros para uma análise organizacional. In: MOTTA, Fernandes C. Prestes. Cultura organizacional e cultura brasileira, São Paulo: Atlas, 1997, Cap. 2.

FREYRE, Gilberto. Casa Grande \& Senzala: formação da família brasileira sob o regime da economia patriarcal / Gilberto Freyre; apresentação de Fernando Henrique Cardoso - 49 ed. Revista - São Paulo: Global, 2004.

GEERTZ, Clifford. A interpretação das culturas. Rio de Janeiro: GuanabaraKoogan, 1989.

GIL, A.C. Métodos e Técnicas de Pesquisa Social. 5 ed. São Paulo : Atlas, 1999.

GILLESPIE, Michael A. et al. Linking organizational culture and customer satisfaction: Results from two companies in different industries. European Journal of Work and Organizational Psychology, v.17, n.1, p.112-132, 2008

BIDO, D.S; GODOY, A.S; FERREIRA, J.F; KENSKI, J.M. Examinando a Relação Entre Aprendizagem Individual, Grupal e Organizacional em uma Instituição Financeira, em XXXII Enanpad - Encontro da Associação Nacional dos Programas de Pós-Graduação em Administração, Rio de Janeiro-RJ, 2008.

HOFSTEDE, Geert et al. Measuring organizational cultures: a qualitative and quantitative study across twenty cases. Administrative Science Quarterly. v.35, n.2, p.286-318, 1990.

HOLANDA, Sérgio Buarque de. Raízes do Brasil. 26 ed. São Paulo: Companhia das Letras, 1995.

MARTIN, Joanne. Organizational Culture: mapping the terrain. London: Sage Publications, 2002.

PÉPIN, Normand. "Cultura de empresa. Nascimento, alcance e limites de um conceito". In: Mosaico Revista de Ciências Sociais, v. 1, n. 1. Vitória: UFES-CEG, 1999. 
PEREIRA, Alexandre. Guia Prático de Utilização do SPSS: análise de dados para ciências sociais e psicologia. 6 ed. Lisboa : Edições Sílabo, 2006

\section{PINTO, Marta Maríci Rímoli Ajej. Cultura} organizacional e características de liderança em empresas de Uberlândia e região. 2005. Dissertação (Mestrado em Psicologia) Programa de Pós-Graduação em Psicologia Mestrado - Universidade Federal de Uberlândia, Uberlândia, 2005.

RICHARDSON, R.J. Pesquisa Social : Métodos e Técnicas. São Paulo : Atlas, 1989.

RIBEIRO, Darcy. O Povo Brasileiro. São Paulo: Companhia das Letras, 2006.

ROUSSEAU, D M. Assessing Organizational Culture: The Case for Multiple Methods. In: Schneider, B. (Org.), Organizational Climate and Culture. San Francisco: Jossey-Bass, 1990.

SCHEIN, Edgar H. Culture; the missing concept in organization studies. Administrative Science

Quarterly, v.41, n.2, p.229-240, 1996.

BIDO, D.S; GODOY, A.S; FERREIRA, J.F; KENSKI, J.M. Examinando a Relação Entre Aprendizagem Individual, Grupal e Organizacional em uma Instituição Financeira, em XXXII Enanpad - Encontro da Associação Nacional dos Programas de Pós-Graduação em Administração, Rio de Janeiro-RJ, 2008.

SMIRCICH, Linda. Concepts of culture and organizational analysis. Administrative Science Quarterly, v.28, n.3, p.339-358, 1983.

SOARES, Rute Cristina Meurer. Estudo das diferenças culturais como empecilho à harmonização contábil: casos do Brasil, EUA e Japão. 2005. 132f. Dissertação (Mestrado em Ciências Contábeis) - Programa de PósGraduação em Ciências Contábeis. Universidade Regional de Blumenau, Blumenau, 2005.

\section{Letícia Rodrigues da Fonseca}

Doutora em Administração pela Universidade Presbiteriana Mackenzie (UPM). Docente do Mestrado em Sustentabilidade em Recursos Hídricos da Universidade Vale do Rio Verde (UninCor).

\section{Sérgio Ricardo Magalhães}

Doutor em Engenharia Biomédica pelo Instituto de Engenharia Biomédica de São José dos Campos (IP\&D). Docente do Mestrado em Sustentabilidade em Recursos Hídricos da Universidade Vale do Rio Verde (UninCor).
Junia Rafael Mendonça Figueiredo

Doutora em Fisiologia Vegetal pela Universidade Federal de Lavras (UFLA). Docente do curso de Agronomia da Universidade Vale do Rio Verde (UninCor).

\section{Glei dos Anjos de Carvalho Castro}

Doutora em Ciências Veterinárias pela Universidade Federal de Lavras (UFLA). Docente do curso de Veterinária da Universidade Vale do Rio Verde (UninCor).

\section{Lepoldo Uberto Ribeiro Júnior}

Doutor em Engenharia Civil pela Universidade Estadual de Campinas (UNICAMP). Docente do curso de Engenharia de Produção do Centro Universitário de Itajubá (FEPI).

\section{Guilherme Marques Pereira}

Doutor em Ciências da Linguagem pela Universidade Vale do Sapucaí - UNIVÁS. 